\title{
Positive ionospheric storm effects at Latin America longitude during the superstorm of 20-22 November 2003: revisit
}

\author{
B. Zhao ${ }^{1,2}$, W. Wan ${ }^{1}$, J. Lei ${ }^{3}$, Y. Wei ${ }^{4}$, Y. Sahai ${ }^{5}$, and B. Reinisch ${ }^{6,7}$ \\ ${ }^{1}$ Beijing National Observatory of Space Environment, Institute of Geology and Geophysics, Chinese Academy of Sciences, \\ Beijing, China \\ ${ }^{2}$ State Key Laboratory of Space Weather, Chinese Academy of Sciences, Beijing, China \\ ${ }^{3}$ School of Earth and Space Sciences, University of Science and Technology of China, Hefei, China \\ ${ }^{4}$ Max-Planck-Institut für Sonnensystemforschung, Katlenburg-Lindau, Germany \\ ${ }^{5}$ Universidade do Vale do Paraíba, Sao Jose dos Campos, Sao Paulo, Brazil \\ ${ }^{6}$ Lowell Digisonde International, LLC, Lowell, MA, USA \\ ${ }^{7}$ Center for Atmospheric Research, University of Massachusetts, Lowell, MA, USA
}

Correspondence to: B. Zhao (zbqjz@ mail.iggcas.ac.cn)

Received: 31 October 2011 - Revised: 15 April 2012 - Accepted: 20 April 2012 - Published: 10 May 2012

\begin{abstract}
Positive ionospheric storm effects that occurred during the superstorm on 20 November 2003 are investigated using a combination of ground-based Global Positioning System (GPS) total electron content (TEC), and the meridian chain of ionosondes distributed along the Latin America longitude of $\sim 280^{\circ}$ E. Both the ground-based GPS TEC and ionosonde electron density profile data reveal significant enhancements at mid-low latitudes over the $280^{\circ} \mathrm{E}$ region during the main phase of the November 2003 superstorm. The maximum enhancement of the topside ionospheric electron content is 3.2-7.7 times of the bottomside ionosphere at the locations of the ionosondes distributed around the midand low latitudes. Moreover, the height of maximum electron density exceeds $400 \mathrm{~km}$ and increases by $100 \mathrm{~km}$ compared with the quiet day over the South American area from middle to low latitudes, which might have resulted from a continuous eastward penetration electric field and storm-generated equatorward winds. Our results do not support the conclusions of Yizengaw et al. (2006), who suggested that the observed positive storm over the South American sector was mainly the consequence of the changes of the bottomside ionosphere. The so-called "unusual" responses of the topside ionosphere for the November 2003 storm in Yizengaw et al. (2006) are likely associated with the erroneous usage of magnetometer and incomplete data.
\end{abstract}

Keywords. Ionosphere (Ionospheric disturbances)

\section{Introduction}

Superstorms, characterised by prolonged periods of extremely high magnetic activity, are always of great interest to the scientific community as they create extremely enhanced electromagnetic fields and particle environments that behave differently than those predicted by conventional theory (Bell, 1997). In the past 23rd solar cycle, several well-known super-storm events have been investigated on the matter of cause-and-effect from their solar origin to the ionospherethermosphere (IT) system. The November 2003 storm is a case-in-point, which is the largest storm in the 23rd solar cycle according to the Dst index (Gopalswamy et al., 2005). Some unique attributions of the IT response to this storm have been revealed through ground- and space-based instruments. For example, the DMSP-F13 spacecraft shows definite evidence of saturation of the cross polar cap potential drop in the Earth's ionosphere (Hairston et al., 2005). Welldeveloped anomalous storm Es layers were observed at latitudes as low as $37^{\circ} \mathrm{N}$ in the European region and at AlmaAta $\left(43.3^{\circ} \mathrm{N}\right)$ in Middle Asia (Blanch et al., 2005; Gordienko et al., 2005). A storm enhanced density (SED) plume in the total electron content (TEC) was observed in the midlatitudes using a network of GPS receivers in North America (Foster et al., 2005; Pokhotelov et al., 2008). The advection of low-latitude dense plasma due to the $\boldsymbol{E} \times \boldsymbol{B}$ drift by the eastward and poleward electric field is thought to be the 
mechanism of SED (Foster and Rideout, 2005). Meanwhile, the dayside source of the polar tongue of ionization (TOI) has been proved to be the plume of SED transported from low latitudes in the post-noon sector by the subauroral disturbance electric field using the global GPS network and SuperDARN and DMSP observations (Foster et al., 2005). At low latitudes, spike-like changes of the equatorial F-region upward $\boldsymbol{E} \times \boldsymbol{B}$ drift were observed with the DMSP and ROCSAT-1 satellite measurements at 14:00, 18:00 and 09:30 LT during the main phase of the magnetic storm (Kil et al., 2007; Heelis and Coley, 2007). This is a consequence of the leakage of the dawn-to-dusk polar cap electric field to lower latitudes known as the prompt penetration electric fields (PPEF) when the interplanetary magnetic field (IMF) has a large southward component (e.g., Fejer et al., 1979; Kelley et al., 1979, 2003). The high-latitude convection and ionospheric potential distribution patterns driven by magnetic field aligned currents are strongly affected by longitudinal and latitudinal variations of the Pedersen and Hall conductivities. Wolf (1970) pointed out for a given ratio of the height integrated Hall to Pedersen conductivities, the enhancement of the auroral conductivities and the divergence-free current condition lead to an eastward rotation of the potential distribution. This skewing effect resulting in the asymmetry of the duration of the local time of the eastward and westward PPEF was clearly indicated by Nopper and Carovillano (1978). On the basis of East Asian ionosonde observations Zhao et al. (2008) proved that the eastward PPEF during this storm occurred not only at daytime and dusk side, but also during the nighttime hours of 20:00-22:00 LT.

Basu et al. (2007) showed that a broad plasma depletion or bite-out tends to occur in the South Atlantic magnetic anomaly (SAMA) region during the storm's main phase as a result of a large zonal electric field that occurs in the dusk sector, as is shown in the case of November 2003 storm and the other known historic events. They proposed that the eastward penetration electric field, associated with rapid Dst decrease, adds to the post-sunset eastward E-field due to the F-region dynamo, which may be specially enhanced in the SAMA longitude because of the increased zonal conductivity gradient caused by energetic particle precipitation (Abdu et al., 2005).

Among the various responses of the IT system during the superstorm on 20 November, it is of great interest to investigate the altitude distributions of the ionosphere plasma under extremely disturbed condition, e.g., the great changes in the electric field, the neutral wind system and the neutral composition. Yuan et al. (2009) reported observations from the GPS TEC, ionosonde and Millstone Hill incoherent scatter radar showing an interesting feature of the height profile of the ionospheric electron density during the passage of the SED plume. During the SED event, the electron density content in the topside ionosphere above $700 \mathrm{~km}$ contributes most of the TEC $(\sim 59 \%)$ during the SED event, while it is less than $1 \%$ of the TEC on a quiet day.
For the superstorm of 20 November 2003, Yizengaw et al. (2006) reported that the topside ionosphere responded unusually as compared to the behaviour observed in a number of other storms. In Yizengaw et al. (2006), the vertical density profiles, constructed from ground-based GPS TEC using a tomographic reconstruction technique, revealed that the ionospheric F2-layer peak height in the mid-low latitude areas of the Southern Hemisphere at $290^{\circ} \mathrm{E}$ had been depressed down to altitudes below the orbiting height of the CHAMP satellite $(\sim 400 \mathrm{~km})$. Furthermore, Yizengaw et al. (2006) showed that the daytime topside ionospheric contribution to the ground-based GPS TEC is usually low $(<20 \%)$, a percentage which is far less than the large increase of the topside ionosphere observed during the 2003 Halloween storm. Mannucci et al. (2005) observed a 900\% increase in electron content above the CHAMP satellite at $\pm 30^{\circ}$ geomagnetic latitudes over the Pacific Ocean.

In this paper, we re-investigated the ionospheric response in the mid-low latitudes at $290^{\circ} \mathrm{E}$ longitude on the basis of the observations from ground GPS network and an ionosonde meridional chain during the November 2003 storm which was studied by Yizengaw et al. (2006). Our observations show that the topside ionosphere in the South American longitude sector contributes a significant increment of TEC during the November 2003 storm, a typical feature during an intense magnetic storm, which is contrary to the results of Yizengaw et al. (2006).

\section{Data sources}

Since the ionosphere represents a dispersive medium, dualfrequency GPS measurements from ground-based receivers can provide measurements of the TEC from the surface of the Earth up to the GPS orbital altitude of $\sim 20200 \mathrm{~km}$. The GPS TEC is primarily dominated by electron densities in the F-region ionosphere especially during the daytime. TEC observations are a useful means for determining the effect of geomagnetic storms on the ionospheric plasma densities (Mendillo, 2006). We use GPS TEC data obtained from the MIT Haystack Observatory Madrigal database (http://www. openmadrigal.org). A detailed description of the processing methods used to obtain the observations of ground-based GPS TEC is given by MAPGPS (Rideout and Coster, 2006). MAPGPS provides estimated values of TEC in $1 \times 1^{\circ}$ bins every $5 \mathrm{~min}$, distributed over locations where GPS data are available.

We also present the simultaneous ionospheric sounding observations at Wallop Island $\left(37.9^{\circ} \mathrm{N}, 284.5^{\circ} \mathrm{E}\right.$, geomagnetic latitude $48.2^{\circ} \mathrm{N}$, data temporal resolution $15 \mathrm{~min}$ ), Ramey $\left(18.5^{\circ} \mathrm{N}, 292.9^{\circ} \mathrm{E}, 28.8^{\circ} \mathrm{N}, 15 \mathrm{~min}\right)$, Jicamarca $\left(12^{\circ} \mathrm{S}, 283.2^{\circ} \mathrm{E}, 1.7^{\circ} \mathrm{S}, 15 \mathrm{~min}\right)$, São José dos Campos (SJC for short, $23.2^{\circ} \mathrm{S}, 314.1^{\circ} \mathrm{E}, 17.6^{\circ} \mathrm{S}, 5 \mathrm{~min}$ ), Port Stanley $\left(51.6^{\circ} \mathrm{S}, 302.1^{\circ} \mathrm{E}, 41.5^{\circ} \mathrm{S}, 30 \mathrm{~min}\right)$ located from middle to equatorial latitudes at Latin America. Digisonde 

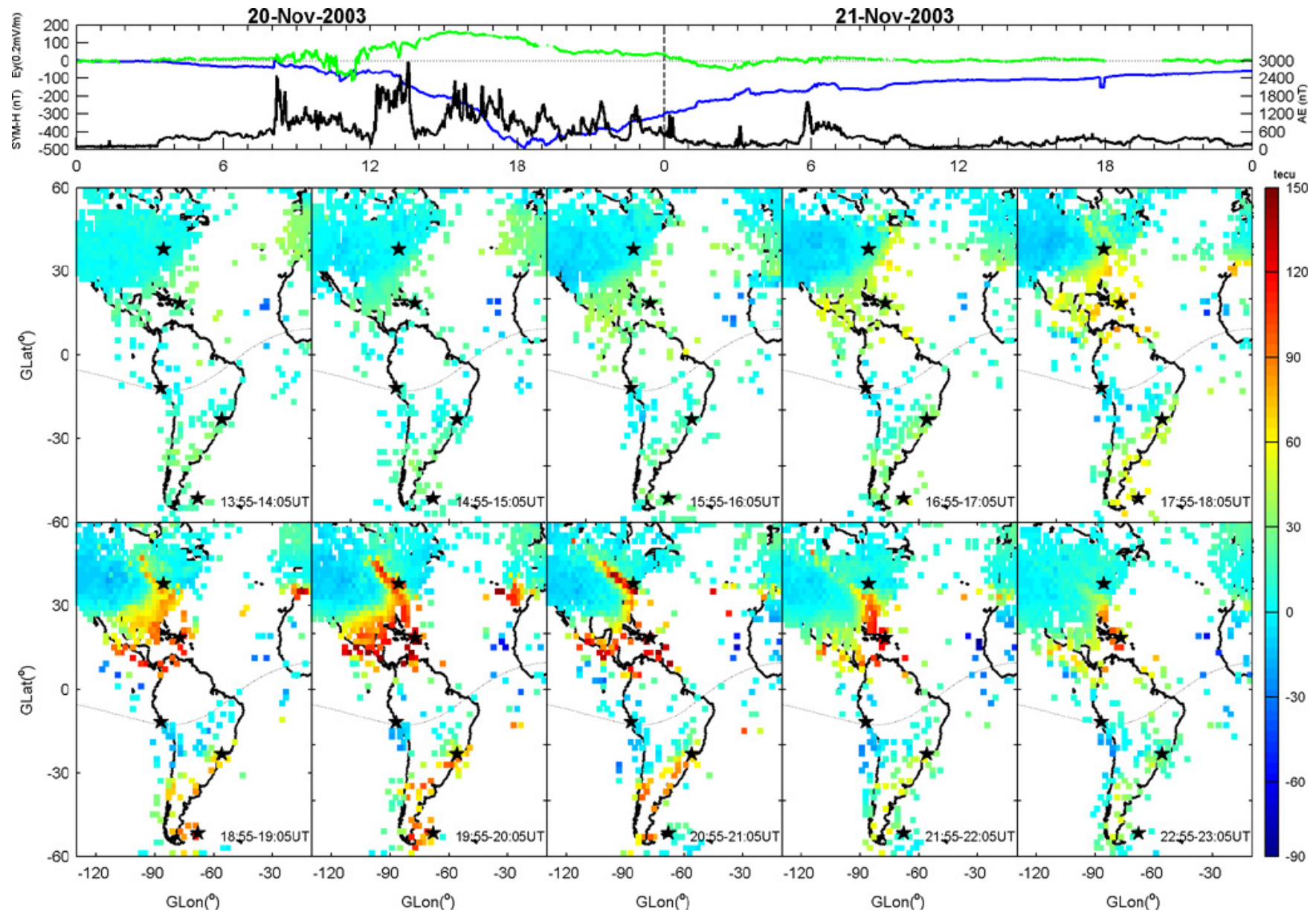

Fig. 1. The top panel shows the SYM-H (blue), AE (black) and IEF $E_{\mathrm{y}}$ (green) from OMNI database. The bottom panels illustrate the differential ground-based GPS TEC from 14:00-23:00 UT between the storm day on 20 November and the undisturbed state on 19 November. The unit of differential TEC is TECu $\left(1 \mathrm{TECu}=10^{16}\right.$ electrons $\left.\mathrm{m}^{2}\right)$. The geomagnetic equator is indicated by the dotted lines and the stars denote the ionosonde stations used in the paper.

measurements at Wallop Island, Ramey, Jicamarca and Port Stanley are taken from the University of Massachusetts Lowell digital ionosonde database at http://giro.uml.edu/ (Reinisch and Galkin, 2011; Khmyrov et al., 2008). The SJC data are from a Canadian Advanced Digital Ionosonde (CADI), which has been transformed from MD4 format into SBF format for manual scaling. The main dataset obtained from this array is the vertical electron density profiles $N(h)$ calculated from the vertical incidence ionograms using the true height profile inversion tool "NHPC" (Huang and Reinisch, 2001). All ionogram scalings have been manually checked using the UMLCAR SAO-Explorer (http:// ulcar.uml.edu) to assure accurate $N(h)$ profiles (Reinisch et al., 2009).

Since an enhancement of PPEF corresponds to an increase of the Pedersen current enhanced by the Cowling effect in the dayside equatorial ionosphere (e.g., Kikuchi and Araki, 1979; Fejer et al., 1979; Kelley et al., 1979, 2003; Araki, 1994), an increase in PPEF results in an enhancement of the eastward equatorial electrojet assuming a constant Cowling conductivity. Anderson et al. (2002) have shown that the difference in the $\mathrm{H}$ component $(\mathrm{dH})$ between a magnetometer on the magnetic equator and one displaced $6 \sim 9^{\circ}$ away can be used to remove the effect of the ring current and deduce the electric field in the equatorial ionosphere. After removing the effect of the ring current on the geomagnetic field at the dip equator during a magnetic storm, the $\mathrm{dH}$ is only proportional to the equatorial ionospheric electric field. The two geomagnetic stations in Peru (LT $=\mathrm{UT}-5 \mathrm{~h}$ ), Jicamarca $\left(\mathrm{JIC}, 11.9^{\circ} \mathrm{S}, 283.1^{\circ} \mathrm{E}\right.$, dip $0.8^{\circ} \mathrm{N}$ ) and Piura (PIU, 5.2 ${ }^{\circ} \mathrm{S}$, $279.4^{\circ} \mathrm{E}$, dip $6.8^{\circ} \mathrm{N}$ ), meet the requirement to estimate the ionospheric electric field.

\section{Observations}

Figure 1 shows global maps of the differential groundbased GPS TEC from 14:00 to 23:00 UT between 19 and 
20 November. The top panel shows the middle latitude geomagnetic index SYM-H (blue), the auroral electrojet index $\mathrm{AE}$ (black), and the dawn-dusk component of interplanetary electric field IEF $E_{\mathrm{y}}$ (green) obtained from the OMNI database. As illustrated in Fig. 1, a positive storm phase over Latin America from middle to low latitudes started to increase significantly $(50 \sim 60 \mathrm{TECU})$ at 17:00 UT with the maximum increment appearing at 20:00-21:00 UT (15:0016:00 LT in Peru local time). Meanwhile, Basu et al. (2007) recorded broad plasma depletions both in the topside ionosphere and equatorial and low latitude TEC over the central and western African regions around 18:15-20:00 UT (18:0020:00 LT in African time), which are consistent with the bottom panels of Fig. 1. At this time the Dst index records a minimum at 21:00 UT (16:00 LT) while the SYM-H and pressure corrected SYM-H* shows double minimums between 18:00 UT and 20:00 UT (Ebihara et al., 2005; Fok et al., 2011). It should be pointed out although the SYM-H is often used as a high resolution index of Dst, its calculation and meaning is a little different (http://wdc.kugi.kyoto-u.ac. jp/aeasy/asy.pdf). The largest enhancements in the Northern Hemisphere are in excess of 150 TECU and these occur around $20^{\circ} \mathrm{N}$. In the Southern Hemisphere, the largest enhancements are about $90 \mathrm{TECU}$ around $50^{\circ} \mathrm{S}$ which is near the latitude of the station Port Stanley. This hemispheric asymmetry was also observed during the initial phase of the storm on 15 December 2006 and is well reproduced using the Coupled Magnetosphere Ionosphere Thermosphere (CMIT) 2.0 model (Lei et al., 2008b). Their model results show that the asymmetry was caused by smaller $-\frac{\partial N}{\partial h}$ in the topside ionosphere at middle latitudes in the Southern Hemisphere because of a larger scale height as a result of higher plasma temperatures in the summer hemisphere and the neutral circulation from the summer to the winter hemisphere. The upward plasma flux due to the transportation of $\boldsymbol{E} \times \boldsymbol{B}$ drift in the top side is larger when $-\frac{\partial N}{\partial h}$ is larger. Besides, it should be noticed that the behaviour of the ionosphere over this station often demonstrates a peculiar behaviour due to its closeness to the South-Atlantic Anomaly (SAA). The geomagnetic field is abnormally weak in the region of the SAA. Particles precipitation from the radiation belts and the resulting heating would be larger in the Southern Hemisphere. These extra forms of heating may strongly affect the F2 region plasma since the plasma has a greater scale height when it is hotter and hence make the increment of TEC not that extraordinary as the northern one.

At middle latitudes in Northern America, a plume of SED, featured by a narrow TEC enhancement extending poleward and sunward, appeared at $\sim 18: 00$ UT and became most significant at 20:00-21:00 UT (Fig. 1). It is shown that the position of the base of the SED plume shifts several degrees lower in latitude starting around 17:30 UT. This is identified by the Millstone ISR $\left(42.6^{\circ} \mathrm{N}\right)$ profiles to 21:00 UT near the station Wallop Island $\left(37.9^{\circ} \mathrm{N}\right)$. This explains why the vertical ionospheric profiles of Millstone ISR only recorded un- usually high densities in the altitude range from $400 \mathrm{~km}$ to above $800 \mathrm{~km}$ between 17:10 UT and 18:30 UT (Foster et al., 2005; Yuan et al., 2009).

The behaviour of the ionosphere in Latin America on the day of the storm 20 November is compared with that on the quiet day, 19 November, using the observations along the $290^{\circ} \mathrm{E}$ meridional ionosonde chain in order to reveal storm effects. In the bottom panels, Fig. 2 displays the ionospheric plasma frequency height profiles in colour as a function of time. The top panels show the associated $\mathrm{dH}_{\mathrm{J}-\mathrm{P}}$ changes. The square and triangle marks denote the peak height of the ionospheric F2 layer ( $h m \mathrm{~F} 2)$ during the quiet and storm day, respectively. The left panel shows the quiet day behaviour for the stations Wallop Island, Ramey, Jicamarca, SJC and Port Stanley arranged according to geomagnetic latitude decreasing from top to bottom. Note that the topside parts of the profiles are approximated by a matched $\alpha$-Chapman function (Huang and Reinisch, 2001).

As seen in Fig. 2, the effect of the ionospheric storm, i.e., the difference of electron density between the disturbed and quiet days, is quite significant. At middle to low latitude stations Wallop Island, Ramey, SJC and Port Stanley, continuous increases in $h m \mathrm{~F} 2(0 \sim 150 \mathrm{~km})$ occurred during 12:0024:00 UT on the disturbed day. A series of electron density enhancements are observed between 16:00 UT (11:00 LT) and 22:00 UT (17:00 LT) at all the middle-low latitude stations, while the most significant one occurred at Wallop Island with a value of $4.7 \times 10^{12} \mathrm{~m}^{-3}$, or $f \circ \mathrm{F} 2=19.4 \mathrm{MHz}$. The phenomenon of an extremely large critical frequency of the F2 layer ( $f o$ F2) at middle latitude also appeared during another SED event observed in the East Asian region for the November 2004 superstorm as reported by Maruyama (2006) who showed that at station Wakkanai $\left(36.4^{\circ} \mathrm{N}\right), f_{o} \mathrm{~F} 2$ reached a maximum value of $18.1 \mathrm{MHz}$ that exceeds the value of $14.3 \mathrm{MHz}$ at Okinawa $\left(16.8^{\circ} \mathrm{N}\right)$ in the equatorial ionization anomaly (EIA) region.

At the equatorial station of Jicamarca, the $h m \mathrm{~F} 2$ shows an evident enhancement that started at around 14:30 UT on 20 compared to the value on 19 November. Meanwhile, $\mathrm{dH}_{\mathrm{J}-\mathrm{P}}$ was observed to have a large positive component of more than 150 nT after 14:30 UT (09:30 LT) and became further increased to $300 \mathrm{nT}$ after 16:00 UT (11:00 LT), indicating a continuous eastward PPEF event. Magnetometer-inferred $\boldsymbol{E} \times \boldsymbol{B}$ drift velocities show that the disturbed upward drift reached $70 \mathrm{~m} \mathrm{~s}^{-1}$ for more than $2 \mathrm{~h}$ (Anderson et al., 2006). Thus, the $h m \mathrm{~F} 2$ was estimated to rise by several hundred kilometres forming an F3 layer at high altitude with the ionogram echo traces finally moving beyond the upper edge of the height range in the ionogram. The residual $\mathrm{F}$ ionization is then forming a new F2 layer in the lower F-region (e.g., Zhao et al., 2005; Paznukhov et al., 2007). During this process, the plasma was pumped away from the equatorial areas due to the fountain effect.

In order to investigate how different the bottomside and topside ionosphere responds to the November storm, a 

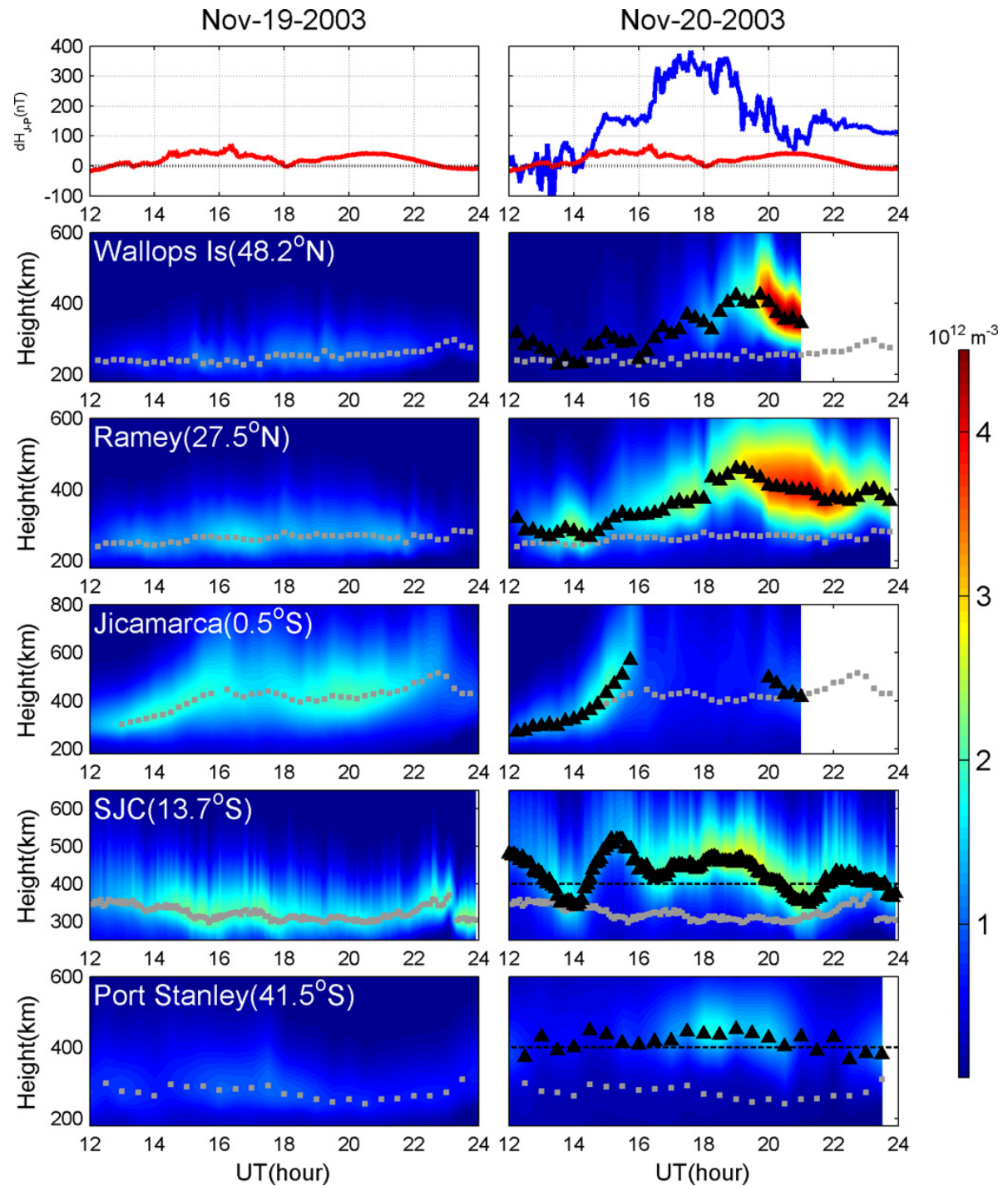

Fig. 2. Electron density profile variations as a function of time for the Latin America sector: (left) quiet day 19 November and (right) 20 November 2003 data. The station name and geomagnetic latitude are labeled on the top of each panel. The F2 layer peak heights are marked by squares for the quiet day and by triangles for the storm day. The horizontal dotted line denotes the altitude of $400 \mathrm{~km}$. The top two panels show $\mathrm{dH}_{\mathrm{J}-\mathrm{P}}$ for the quiet day (left and red) and the storm day (right and blue).

comparison was made between the GPS TEC, ionogram bottomside TEC (BTEC) and topside TEC (TTEC=GPS TECBTEC). The GPS TEC for the ionosonde locations was approximated by the mean value of a nearby MAPGPS TEC value in a $2^{\circ}$ (latitude) $\times 4^{\circ}$ (longitude) bin. We applied the Romberg integration to calculate the BTEC from the profile curve within boundary of $150-h m F 2(\mathrm{~km})$ as it has the advantage of fast convergence and high degree of accuracy. The $h m \mathrm{~F} 2$ is identified by the altitude of the maximum electron density of the profile. The left panels of Fig. 3 display GPS TEC, BTEC and TTEC at all stations during 19 November. It can be seen from Fig. 3 that the TTEC is approximately 2 times of BTEC, representing roughly the 2/3 of the TEC during the daytime on quiet day 19 November at Wallop Island,
Ramey and Port Stanley. At the equatorial station Jicamarca, TTEC is comparable to the BTEC. The difference could be mainly due to the fact that the plasma density at equatorial topside ionosphere is drained away from the equator under the combination of electrodynamic and gravitational ambipolar diffusion effects.

The right panels of Fig. 3 illustrate the differential value of GPS TEC, BTEC and TTEC between 19 and 20 November. The maximum increases of $\triangle \mathrm{BTEC}$ reach $30,35,20$ and 13 TECU at the Wallop Island, Ramey, SJC and Port Stanley stations, and the corresponding increases of $\triangle$ TTEC are 115 , 124, 64 and 100 TECU. The increase of the electron content in the topside ionosphere is considerably more evident than that in the bottomside as $\triangle T T E C / \triangle B T E C$ is approximately 

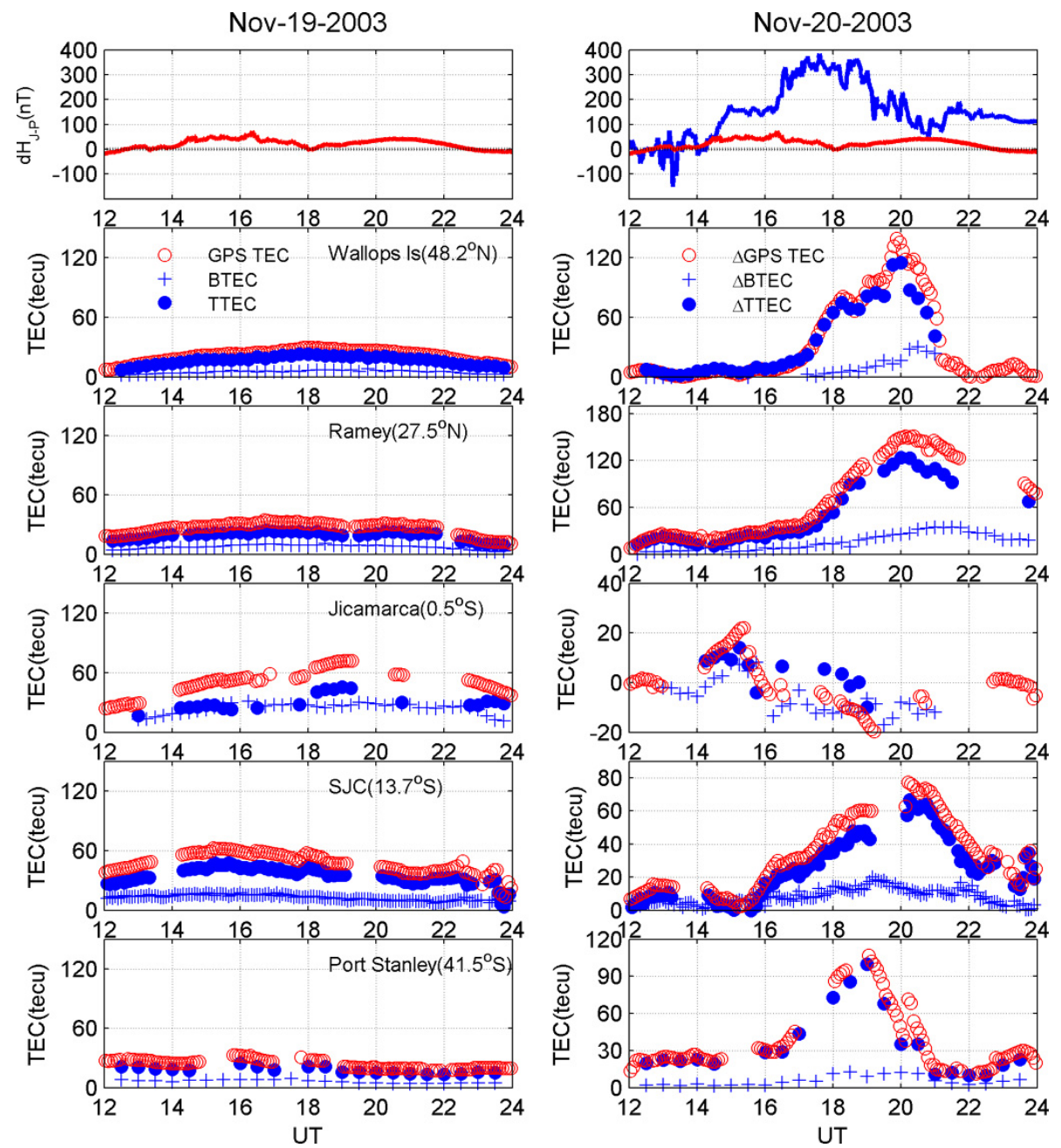

Fig. 3. Ionosonde bottomside TEC (BTEC), topside ionospheric TEC (TTEC) and GPS TEC variations as a function of time for the Latin America sector: (left) quiet day 19 November and (right) difference value of each parameter after subtracting the quiet day value on the storm day 20 November 2003. The station name and geomagnetic latitude are labeled on top of each quiet-day panel. The top two panels show $\mathrm{dH}_{\mathrm{J}-\mathrm{P}}$ for the quiet day (red) and the storm day (blue).

3.8, 3.5, 3.2 and 7.7. It is apparent that the maximum enhancement of the topside TEC at station Port Stanley is larger than that at low latitude station of SJC, and that the most significant increases in the GPS TEC are near the location at geographic latitude $54^{\circ} \mathrm{S}$ and longitude $70^{\circ} \mathrm{W}$ with maximum value reaching 113 TECU at around 19:00 UT. This anomalous topside enhancement suggests that a possible SED event occurred in the Southern Hemisphere, at a conjugate location to that of the one observed in the Northern Hemisphere which has been observed in other intense storms (Foster and Coster, 2007).

\section{Discussions}

As shown in Fig. 1, the unusual ionospheric response of this superstorm is the feature described by Mannucci et al. (2008) that the largest TEC increases appear several hours (5-7) following the interplanetary magnetic field $B_{\mathrm{Z}}$ event onset. In our study, the delay is $7-8 \mathrm{~h}$ at Wallop Island, Ramey, SJC and Port Stanley. The large increase in time delay should be mainly attributed to the influence of the solar wind dynamic pressure $\left(P_{\mathrm{SW}}\right)$ on PPEF at the low-latitude ionosphere. The $P_{\mathrm{SW}}$ jumps from 3.4 to $15.2 \mathrm{nPa}$ under stable southward IMF $\mathrm{Bz}$ conditions, corresponding to the step-like increase in $\mathrm{dH}_{\mathrm{J}-\mathrm{P}}$ around 16:30 UT, i.e., $5 \mathrm{~h}$ later after the IMF $B_{\mathrm{Z}}$ orientation changes to southward. Therefore, the "delay" is essentially a combined consequence of the large sustained southward IMF $B_{\mathrm{Z}}$ and $P_{\mathrm{SW}}$ jump. The former quickly results in a saturation of the cross polar cap potential drop after the IMF turns southward and, thus, the PPEF, which is controlled by the cross polar cap potential drop, decouples from the IMF variations and couples to the $P_{\mathrm{SW}}$; the latter drives a PPEF enhancement around 16:30 UT and then 
causes disturbances in TEC and other parameters (Wei et al., 2012). In other words, the "delay" time is determined by the time interval between the large sustained southward IMF $B_{\mathrm{Z}}$ and $P_{\mathrm{SW}}$ jump, rather than the response of ionospheric electrodynamics processes.

For the November 2003 superstorm, we have also shown that the response of the middle and low latitude ionospheric disturbances could be better ordered in terms of Dst variations. This is characterised by the evidence that the maximum ionospheric disturbance develops and forms during 18:0020:00 UT corresponding to the minimum phase of Dst index or SYM-H index and large broad plasma depletions of topside ionosphere were recorded during this interval (Basu et al., 2007). The above mentioned $P_{\mathrm{SW}}$ related PPEF may link the ionospheric response at middle and low latitude with the evolution of storm ring current. As the PPEF has both the eastward and northward components, the plasma is then transported from the low latitude to the middle latitude and drift westward forming a SED plume (Foster et al., 2002, 2004). Meanwhile mid-latitude SED is carried by high-latitude convection as a tongue of ionization through the cusp, into the polar cap and the nightside auroral oval, which contribute to the outflow of ionospheric species into the magnetosphere and has possible influence on storm-time particle injection (Foster et al., 2005; Yuan et al., 2008). On the other hand, the ions and electrons of the plasma sheet are expected to travel deeply earthward under this strong penetrating electric field, forming a very close strong ring current belt $(L \sim 1.5)$ causing the minimum phase of Dst index as simulated by Fok et al. (2011).

One also can notice that during the SED event 19:0020:00 UT, the topside electron content $\triangle$ TTEC increases significantly compared to the BTEC at station Wallop Island. After 20:00 UT, $\triangle$ TTEC rapidly decreased while $\triangle \mathrm{BTEC}$ started to increase. Meanwhile, Fig. 2 shows that the peak height of the ionospheric F2 layer increased from $400 \mathrm{~km}$ to $420 \mathrm{~km}$ during 19:30-19:45 UT, then kept decreasing to $350 \mathrm{~km}$ until 20:30 UT while the corresponding foF 2 increased from $13.2 \mathrm{MHz}$ to $16.5 \mathrm{MHz}$ and kept increasing until 19.4 MHz. Similar feature occurred at station Ramey, but with smaller increased $f o \mathrm{~F} 2$ and slowly decreased $h m \mathrm{~F} 2$. This approximate anticorrelation between $h m \mathrm{~F} 2$ and $N m \mathrm{~F} 2$ has been investigated by Lu et al. (2001) showing a possible mechanism resulting from vertical transport of plasma by the gravity wave winds. The poleward winds with vertical shear can lead to decreases of $h m \mathrm{~F} 2$ and a continuous increase of $N m \mathrm{~F} 2$. It is not clear that the poleward winds were caused by travelling atmospheric disturbances (TADs) from the Northern polar region or the one from the Southern Hemisphere that cross the equator. Simulation results from Lei et al. (2008a) show that the daytime TADs launched from the Southern Hemisphere can penetrate to the high latitude Northern Hemisphere and last for more than $4 \mathrm{~h}$. They have also pointed out that the ionospheric oscillations seen in observations are not necessarily induced by the TADs and they can be caused by the disturbed winds due to the large scale summer-to-winter thermospheric circulation during storm periods. Therefore, a combination of $\boldsymbol{E} \times \boldsymbol{B}$ and poleward disturbed winds possibly caused by TADs, are the main cause for the formation of an anomalously large $N m \mathrm{~F} 2$ value.

Yizengaw et al. (2006) claimed that the topside ionosphere responded unusually to the 20 November 2003 severe storm compared to behaviour observed in a number of previous storms. Yizengaw et al. (2006) first presented observations by the ground-based GPS receivers which show a large enhancement in dayside TEC and by the low-Earth orbiting $(400 \mathrm{~km})$ CHAMP satellite which did not show any sign of a dayside TEC enhancement. We may notice that the UT and LT of the CHAMP orbit passing the Peruvian longitude is around 15:00-16:00 UT (10:00-11:00 LT) while the most significant increase of ground GPS TEC occurred at 20:0021:00 UT (15:00-16:00 LT). In fact, if we compare the two datasets for the same UT time, the CHAMP TEC increment ( $\sim 30$ TECU) in the southern EIA region at Peruvian longitude is comparable to the increment of GPS TEC (their Figs. 4 and 6).

Yizengaw et al. (2006) have shown that the vertical density profiles, constructed from ground-based GPS TEC using a tomographic reconstruction technique, clearly revealed that the ionospheric $h m \mathrm{~F} 2$ at Peruvian longitude had been depressed down to lower altitudes around $\sim 350 \mathrm{~km}$. Yizengaw et al. (2006) proposed that a westward disturbance dynamo electric field may push ionospheric plasma down to the low altitude in order to explain the tomographic ionospheric profiles based on the observation of two magnetometers at the equatorial station Huancayo $\left(12.05^{\circ} \mathrm{S}, 284.67^{\circ} \mathrm{E}\right)$ and the non-equatorial station San Juan $\left(18.38^{\circ} \mathrm{N}, 293.88^{\circ} \mathrm{E}\right)$. However, our results in Fig. 2 show that $h m \mathrm{~F} 2$ on the storm day at SJC and Port Stanley remained above $400 \mathrm{~km}$ altitude for most of the time during the southward turning of IMF $B_{\mathrm{Z}}$. Sometimes the $h m \mathrm{~F} 2$ increases more than $100 \mathrm{~km}$ compared with the value on the quiet day. Yizengaw et al. (2006) illustrates that the $\mathrm{dH}\left(H_{\mathrm{Hua}}-H_{\mathrm{Sjg}}\right)$ component has a large negative value during 15:00-19:30 UT. However, we downloaded magnetometer data and recalculated them and compared our results with their curve. The comparison shows that before 12:00 UT and after 19:30 UT on 20 November, our curve behaves the same as what they show. However, during 12:0019:30 UT, our curve of $\mathrm{dH}$ is just opposite to their result. Our evolution of $\mathrm{dH}\left(H_{\mathrm{Hua}}-H_{\mathrm{Sjg}}\right)$ resembles the curve of $\mathrm{dH}$ $\left(H_{\mathrm{Jic}}-H_{\mathrm{Piu}}\right)$ used in this work. Thus, we believe that the authors made a mistake of $\mathrm{dH}\left(H_{\mathrm{Hua}}-H_{\mathrm{Sjg}}\right)$ during the interval 12:00-19:30 UT which shows a clear large positive value indicating an eastward PPEF event.

From the point of view of altitude differential response, the ionospheric effects over Latin America during the main phase of the November superstorm is not unusual. The plasma density in the topside ionosphere increase much more than in the bottomside on the storm day compared to the 
quiet value as shown in Fig. 3. The feature is similar to the response of the topside ionosphere of the Halloween storm for the 29 and 30 October 2003 events, although the enhancement of the topside ionosphere was more evident at mid-latitudes compared to the pre-storm level (Mannucci et al., 2005). Astafyeva (2009) has also shown that severe enhancements (up to $\sim 350 \%$ ) of the equatorial and midlatitude TEC above $\sim 430 \mathrm{~km}$ with concurrent travelling of the equatorial anomaly crests for a distance of $10-15^{\circ}$ of latitude were observed during superstorms on 6 November 2001 and 8 November 2004. The mechanism of the anomalous enhancement of the topside TEC at mid-low latitudes during the superstorm was explained as an effect of poleward displacement of the equatorial anomaly peaks in the presence of enhanced outward meridional $\boldsymbol{E} \times \boldsymbol{B}$ drifts during large PPEF event (Tsurutani et al., 2004). It should also be pointed out that Rishbeth et al. (2010) commented that local change in ionization production, due to the elevation of plasma induced by the local storm wind and electric fields, should be considered as a more important process for producing plasma density enhancements than transport from a more remote source of enhanced density.

\section{Conclusions}

In this study we revisited the positive ionospheric storm effects along the Latin America longitude during the superstorm on 20 November 2003. Both the ground-based GPS TEC and ionosonde electron density profile data show significant enhancements at mid-low latitudes over the $280^{\circ} \mathrm{E}$ region during the main phase of this storm. Furthermore, the height of maximum electron density exceeds $400 \mathrm{~km}$ and increases by $100 \mathrm{~km}$ compared with the quiet day over the South American area from middle to low latitudes. Consequently, electron density in the topside has a much stronger enhancement than that in the bottomside of the ionosphere associated with a continuous eastward penetration electric field and storm-generated equatorward winds. Thus, the unusual responses of the topside ionosphere reported by Yizengaw et al. (2006) are not supported by our observation and are likely associated with the erroneous usage of magnetometer and incomplete data.

Acknowledgements. This research was supported by the National Natural Science Foundation of China (41174138), the National Important Basic Research Project of China (2011CB811405), the Open Research Program of the State Key Laboratory of Space Weather, Chinese Academy of Sciences and 100 Talents Programme of the Chinese Academy of Science (to J. Lei). We acknowledge the CDAWeb for access to the OMNI data. Special thanks should be given to Anthea Coster for providing MIT_TEC data. The Jicamarca Radio Observatory is a facility of the Instituto Geofísico del Perú operated with support from the NSF Cooperative Agreement ATM-0432565 through Cornell University.
Topical Editor K. Kauristie thanks two anonymous referees for their help in evaluating this paper.

\section{References}

Abdu, M. A., Batista, I. S., Carrasco, A. J., and Brum, C. G. M.: South Atlantic magnetic anomaly, ionization: A review and a new focus on electrodynamic effects in the equatorial ionosphere, J. Atmos. Solar Terr.Phys., 67, 1643-1657, 2005.

Anderson, D., Anghel, A., Yumoto, K., Ishitsuka, M., and Kudeki, E.: Estimating daytime vertical $\boldsymbol{E} \times \boldsymbol{B}$ drift velocities in the equatorial $\mathrm{F}$ region using ground-based magnetometer observations, Geophys. Res. Lett., 29, 1596, doi:10.1029/2001GL014562, 2002.

Anderson, D., Anghel, A., Araujo, E., Eccles, V., Valladares, C., and Lin, C.: Theoretically modeling the lowlatitude, ionospheric response to large geomagnetic storms, Radio Sci., 41, RS5S04, doi:10.1029/2005RS003376, 2006.

Araki, T.: A physical model of the geomagnetic sudden commencement, Geophys. Monogr., 81, 183-200, 1994.

Astafyeva, E.: Effects of strong IMF $B_{\mathrm{Z}}$ southward events on the equatorial and mid-latitude ionosphere, Ann. Geophys., 27, 1175-1187, doi:10.5194/angeo-27-1175-2009, 2009.

Basu, S., Basu, Su., Rich, F. J., Groves, K. M., MacKenzie, E., Coker, C., Sahai, Y., Fagundes, P. R., and Becker-Guedes, F.: Response of the equatorial ionosphere at dusk to penetration electric fields during intense magnetic storms, J. Geophys. Res., 112, A08308, doi:10.1029/2006JA012192, 2007.

Bell, J., Gussenhoven, M., and Mullen, E.: Super storms, J. Geophys. Res., 102, 14189-14198, 1997.

Blanch, E., Altadill, D., Boška, J., Burešová, D., and HernándezPajares, M.: November 2003 event: effects on the Earth's ionosphere observed from ground-based ionosonde and GPS data, Ann. Geophys., 23, 3027-3034, doi:10.5194/angeo-23-30272005, 2005.

Ebihara, Y., Fok, M.-C., Sazykin, S., Thomsen, M. F., Hairston, M. R., Evans, D. S., Rich, F. J., and Ejiri, M.: Ring current and the magnetosphere-ionosphere coupling during the superstorm of 20 November 2003, J. Geophys. Res., 110, A09S22, doi:10.1029/2004JA010924, 2005.

Fejer, B. G., Gonzales, C. A., Farley, D. T., Kelley, M. C., and Woodman, R. F.: Equatorial electric fields during magnetically disturbed conditions: 1 . The effect of the interplanetary magnetic field, J. Geophys. Res., 84, 5797-5802, 1979.

Fok, M.-C., Moore, T. E., Slinker, S. P., Fedder, J. A., Delcourt, D. C., Nosé, M., and Chen, S.-H.: Modeling the superstorm in November 2003, J. Geophys. Res., 116, A00J17, doi:10.1029/2010JA015720, 2011.

Foster, J. C. and Coster, A. J.: Conjugate localized enhancement of total electron content at low latitudes in the American sector, J. Atmos. Sol. Terr. Phys., 69, 1241-1252, doi:10.1016/j.jastp.2006.09.012, 2007.

Foster, J. C. and Rideout, W.: Midlatitude TEC enhancements during the October 2003 superstorm, Geophys. Res. Lett., 32, L12S04, doi:10.1029/2004GL021719, 2005.

Foster, J. C., Erickson, P. J., Coster, A. J., Goldstein, J., and Rich, F. J.: Ionospheric signatures of plasmaspheric tails, Geophys. Res. Lett., 29, 1623, doi:10.1029/2002GL015067, 2002. 
Foster, J. C., Coster, A. J., Erickson, P. J., Rich, F. J., and Sandel, B. R.: Stormtime observations of the flux of plasmaspheric ions to the dayside cusp/magnetopause, Geophys. Res. Lett., 31, L08809, doi:10.1029/2004GL020082, 2004.

Foster, J. C., Coster, A. J., Erickson, P. J., Holt, J. M., Lind, F. D., Rideout, W., McCready, M., van Eyken, A., Greenwald, R. A., and Rich, F. J.: Multiradar observations of the polar tongue of ionization, J. Geophys. Res., 110, A09S31, doi:10.1029/2004JA010928, 2005.

Gopalswamy, N., Yashiro, S., Michalek, G., Xie, H., Lepping, R. P., and Howard, R. A.: Solar source of the largest geomagnetic storm of cycle 23, Geophys. Res. Lett., 32, L12S09, doi:10.1029/2004GL021639, 2005.

Gordienko, G. I., Vodyannikov, V. V., and Yakovets, A. F.: Ionospheric disturbances over Alma-Ata during the OctoberNovember 2003 magnetic storms, J. Geophys. Res., 110, A09S35, doi:10.1029/2004JA010945, 2005.

Hairston, M. R., Drake, K. A., and Skoug, R.: Saturation of the ionospheric polar cap potential during the OctoberNovember 2003 superstorms, J. Geophys. Res., 110, A09S26, doi:10.1029/2004JA010864, 2005.

Heelis, R. A. and Coley, W. R.: Variations in the low- and middle-latitude topside ion concentration observed by DMSP during superstorm events, J. Geophys. Res., 112, A08310, doi:10.1029/2007JA012326, 2007.

Huang, X. and Reinisch, B. W.: Vertical electron content from ionograms in real time, Radio Sci., 36, 335-342, doi:10.1029/1999RS002409, 2001.

Kelley, M. C., Fejer, B. G., and Gonzales, C. A.: An explanation for anomalous equatorial ionospheric electric field associated with a northward turning of the interplanetary magnetic field, Geophys. Res. Lett., 6, 301-304, 1979.

Kelley, M. C., Makela, J. J., Chau, J. L., and Nicolls, M. J.: Penetration of the solar wind electric field into the magnetosphere/ionosphere system, Geophys. Res. Lett., 30,1158, doi:10.1029/2002GL016321, 2003.

Khmyrov, G. M., Galkin, I. A., Kozlov, A. V., Reinisch, B. W., McElroy, J., and Dozois, C.: Exploring digisonde ionogram data with SAO-X and DIDBase, AIP Conf. Proc., 974, 175-185, 2008.

Kikuchi, T. and Araki, T.: Horizontal transmission of the polar electric field to the equator, J. Atmos. Sol. Terr. Phys., 41, 917-940, 1979.

Kil, H., Oh, S.-J., Paxton, L. J., Zhang, Y., Su, S.-Y., and Min, K.W.: Spike-like change of the vertical $\boldsymbol{E} \times \boldsymbol{B}$ drift in the equatorial region during very large geomagnetic storms, Geophys. Res. Lett., 34, L09103, doi:10.1029/2007GL029277, 2007.

Lei, J., Burns, A. G., Tsugawa, T., Wang, W., Solomon, S. C., and Wiltberger, M.: Observations and simulations of quasiperiodic ionospheric oscillations and large-scale traveling ionospheric disturbances during the December 2006 geomagnetic storm, J. Geophys. Res., 113, A06310, doi:10.1029/2008JA013090, 2008a.

Lei, J., Wang, W., Burns, A. G., Solomon, S. C., Richmond, A. D., Wiltberger, M., Goncharenko, L. P., Coster, A., and Reinisch, B. W.: Observations and simulations of the ionospheric and thermospheric response to the December 2006 geomagnetic storm: Initial phase, J. Geophys. Res., 113, A01314, doi:10.1029/2007JA012807, 2008b.
Lu, G., Richmond, A. D., Roble, R. G., and Emery, B. A.: Coexistence of ionospheric positive and negative storm phase under northern winter conditions: A case study, J. Geophys. Res., 106, 24493-24504, doi:10.1029/2001JA000003, 2001.

Mannucci, A. J., Tsurutani, B. T., Iijima, B. A., Komjathy, A., Saito, A., Gonzalez, W. D., Guarnieri, F. L., Kozyra, J. U., and Skoug, R.: Dayside global ionospheric response to the major interplanetary events of October 29-30, 2003 "Halloween Storms", Geophys. Res. Lett., 32, L12S02, doi:10.1029/2004GL021467, 2005.

Mannucci, A. J., Tsurutani, B. T., Abdu, M. A., Gonzalez, W. D., Komjathy, A., Echer, E., Iijima, B. A., Crowley, G., and Anderson, D.: Superposed epoch analysis of the dayside ionospheric response to four intense geomagnetic storms, J. Geophys. Res., 113, A00A02, doi:10.1029/2007JA012732, 2008.

Maruyama, T.: Extreme enhancement in total electron content after sunset on 8 November 2004 and its connection with storm enhanced density, Geophys. Res. Lett., 33, L20111, doi:10.1029/2006GL027367, 2006.

Mendillo, M.: Storms in the ionosphere: Patterns and processes for total electron content, Rev. Geophys., 44, RG4001, doi:10.1029/2005RG000193, 2006.

Nopper, R. and Carovillano, R.: Polar-equatorial coupling during magnetically active periods, Geophys. Res. Lett., 5, 699-702, doi:10.1029/GL005i008p00699, 1978.

Paznukhov, V. V., Reinisch, B. W., Song, P., Huang, X., Bullett, T. W., and Veliz, O.: Formation of an F3 layer in the equatorial ionosphere: A result from strong IMF changes, J. Atmos. Sol. Terr. Phys., 69, 1292-1304, doi:10.1016/j.jastp.2006.08.019, 2007.

Pokhotelov, D., Mitchell, C. N., Spencer, P. S. J., Hairston, M. R., and Heelis, R. A.: Ionospheric storm time dynamics as seen by GPS tomography and in situ spacecraft observations, J. Geophys. Res., 113, A00A16, doi:10.1029/2008JA013109, 2008.

Reinisch, B. W. and Galkin, I. A.: Global ionospheric radio observatory (GIRO), Earth Planets Space, 63, 377-381, doi:10.5047/eps.2011.03.001, 2011.

Reinisch, B. W., Galkin, I. A., Khmyrov, G. M., Kozlov, A. V., Bibl, K., Lisysyan, I. A., Cheney, G. P., Huang, X., Kitrosser, D. F., Paznukhov, V. V., Luo, Y., Jones, W., Stelmash, S., Hamel, R., and Grochmal, J.: New Digisonde for research and monitoring applications, Radio Sci., 44, RS0A24, doi:10.1029/2008RS004115, 2009.

Rideout, W. and Coster, A.: Automated GPS processing for global total electron content data, GPS Solutions, 10, 219-228, doi:10.1007/s10291-006-0029-5, 2006.

Rishbeth, H., Heelis, R. A., Makela, J. J., and Basu, S.: Storming the Bastille: the effect of electric fields on the ionospheric F-layer, Ann. Geophys., 28, 977-981, doi:10.5194/angeo-28-977-2010, 2010.

Tsurutani, B., Mannucci, A., Iijima, B., Abdu, M. A., Humberto, J., Sobral, A., Gonzalez, W., Guarnieri, F., Tsuda, T., Saito, A., Yumoto, K., Fejer, B., Fuller-Rowell, T. J., Kozyra, J., Foster, J. C., Coster, A., and Vasyliunas, V. M.: Global dayside ionospheric uplift and enhancement associated with interplanetary electric fields, J. Geophys. Res., 109, A08302, doi:10.1029/2003JA010342, 2004.

Wei, Y., Wan, W., Ridley, A., Zhao, B., Hong, M., Fraenz, M., and Dubinin, E.: Solar wind density controlling the penetration electric field at the equatorial ionosphere during a long-duration saturation of cross polar cap potential, Geophys. Res. Lett., in review, 
2012.

Wolf, R. A.: Effects of ionospheric conductivity on convective flow of plasma in the magnetosphere, J. Geophys. Res., 75, 46774698, doi:10.1029/JA075i025p04677, 1970.

Yizengaw, E., Moldwin, M. B., Komjathy, A., and Mannucci, A. J.: Unusual topside ionospheric density response to the November 2003 superstorm, J. Geophys. Res., 111, A02308, doi:10.1029/2005JA011433, 2006.

Yuan, Z.-G., Deng, X.-H., and Wang, J.-F.: DMSP/GPS observations of intense ion upflow in the midnight polar ionosphere associated with the SED plume during a super geomagnetic storm, Geophys. Res. Lett., 35, L19110, doi:10.1029/2008GL035462, 2008.
Yuan, Z.-G., Deng, X. H., Zhang, S., Wan, W., and Reinisch, B. W.: F-region behaviour in the SED plume during a super geomagnetic storm: A case study, J. Geophys. Res., 114, A08303, doi:10.1029/2008JA013841, 2009.

Zhao, B., Wan, W., and Liu, L.: Responses of equatorial anomaly to the October-November 2003 superstorms, Ann. Geophys., 23, 693-706, doi:10.5194/angeo-23-693-2005, 2005.

Zhao, B., Wan, W., Tschu, K., Igarashi, K., Kikuchi, T., Nozaki, K., Watari, S., Li, G., Paxton, L. J., Liu, L., Ning, B., Liu, J.-Y., Su, S.-Y., and Bulanon, H. P.: Ionosphere disturbances observed throughout Southeast Asia of the superstorm of 20-22 November 2003, J. Geophys. Res., 113, A00A04, doi:10.1029/2008JA013054, 2008. 